\title{
Dentists: "Working to empower smiles"
}

\author{
Saravana Karthikeyan Balasubramanian ${ }^{1 *}$, Shashi Rashmi Acharya ${ }^{2}$, Divya Vinayachandran ${ }^{3}$, \\ Lingeshwar Deenadayalan ${ }^{4}$ \\ ${ }^{1}$ Reader, Conservative Dentistry and Endodontics, SRM Dental College and Hospital, Ramapuram, SRM University, Chennai, India. \\ ${ }^{2}$ Professor, Conservative Dentistry and Endodontics, Manipal College of Dental Sciences, Manipal University, Manipal, India. \\ ${ }^{3}$ Senior Lecturer, Oral Medicine and Radiology, SRM Dental College and Hospital, Kattankulathur, SRM University, Chennai, India. \\ ${ }^{4}$ Assistant Professor, Royapettah Government Hospital, Chennai, India.
}

Received: May 05, 2017; Accepted: May 10, 2017; Published: May 20, 2017

*Corresponding author: Saravana Karthikeyan Balasubramanian, Conservative Dentistry and Endodontics, SRM Dental College and Hospital, Ramapuram, Chennai- 600089, Tamil Nadu, India, Tel:+91-8939471176;Email id: skmdc2006@gmail.com

\section{Dear Sir,}

Spacing between the maxillary anterior teeth is highly unpleasant, unesthetic and may be considered a great social embarrassment to the patient, badly affecting his/her selfconfidence. Kerosuo, et al. (1) in a study reported that the influence of incisal malocclusion on social attractiveness of patients with a broad midline diastema was perceived as being less socially successful and of lower intelligence, particularly in young adults (1). Diastemas can be treated in a multitude of ways including orthodontic closure, restorative and aesthetic therapies, surgical correction or multidisciplinary approach, based on the etiology of that particular case $(2,3)$. Diastemas based on tooth-size discrepancy are most often amenable to simple restorative therapies, however, an adequate case selection and meticulous treatment planning is an essential requisite for the success, as stated by Bolton WA. $(4,5)$. The restorative closure of diastemas can be achieved by using any of the following methods: direct/free hand composite build up with minimal/no tooth preparation, direct composite veneers, indirect composite veneers, porcelain laminate veneers, all ceramic crowns, metal ceramic crowns and composite crowns (6). Though excellent aesthetics is possible with indirect restorations, it is done at the expense of a sound healthy tooth structure in order to achieve the desired results. But this might affect the long term success of the restoration, particularly in young patients, where the pulp chamber is too large and wide. Hence, whenever possible, tooth material augmentation versus tooth material amputation allows for a more conservative treatment option. Also, the increased patient demand for minimally invasive aesthetic procedures in concomitant with the improved physical and aesthetic properties of current composite materials have resulted in the extensive utilization of direct bonding of composite resin to anterior teeth (7). With the careful manipulation of modern composite restorative materials, it is possible to create good quality aesthetic restorations with sufficient wear resistance providing satisfactory years of service. Hence, direct resin build up can be a worthy treatment choice for management of spacing between the anterior teeth, caused as a result of tooth-size discrepancy. In this light, we would like to share our personal clinical experience, where we encountered a 23 year old female patient with a chief complaint of generalized spacing in her maxillary anterior teeth. Her half hidden, reluctant smile caught our attention. Eventually we understood that her non-aesthetic appearance fuelled her low self-esteem. Her history revealed a childhood habit of tongue thrusting with a positive familial history of the same problem. A diagnosis of Class I malocclusion with generalized spacing in the maxillary arch (Figure 1) was made and various treatment options including interventional orthodontic treatment, aesthetic porcelain veneers and conservative direct resin build up were proposed to the patient.

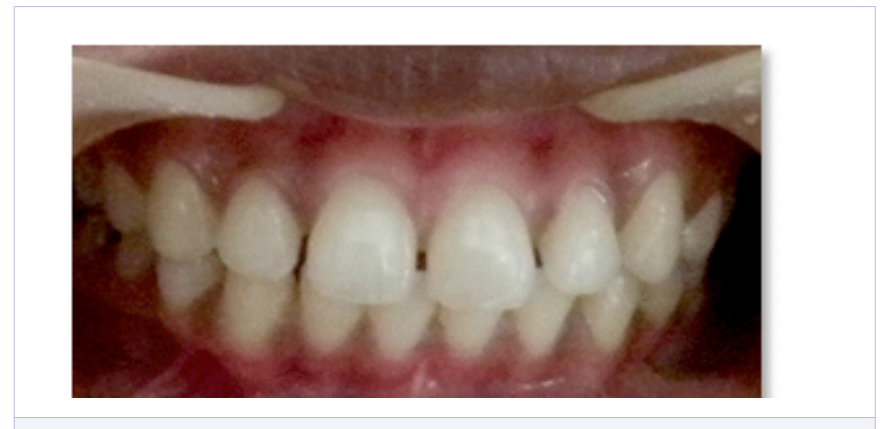

Figure 1

The patient's demand for a minimally invasive restorative technique, her reluctance for interventional management options such as orthodontic treatment and other indirect restorations, in addition, to her economical factor as a limiting constraint, an ultra-conservative approach of direct composite resin build up with reference to the maxillary anterior teeth was considered which finally restored the patient's smile (Figure 2). 


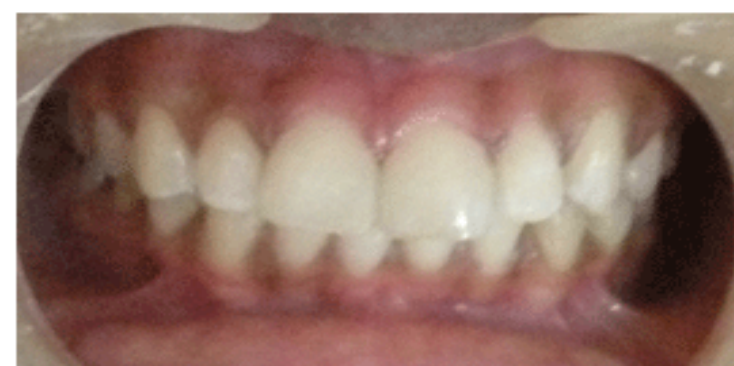

Figure 2

At the end of the procedure, we had the professional satisfaction of seeing the appreciation and confidence in her eyes rather than in her smiles. Sometimes, that moment of selfsatisfaction in our accomplishment adds to our pride to be part of this esteemed profession.

\section{References}

1. Kerosuo H, Hausen H, Laine T, Shaw WC. The influence of incisal malocclusion on the social attractiveness of young adults in Finland. Eur J Orthod. 1995;17(6):505-512.

2. Dlugokinski MD, Frazier KB, Goldstein RE. Restorative treatment of Diastema. In: Esthetic in Dentistry (Vol.2). RE Goldstein, VB Hoywood (Eds.); 2nd Edn.; BC Decker Inc. London, 2002;703-732.

3. Edwards JG. The diastema, the frenum, the frenectomy: a clinical study. Am J Orthod. 1977;71(5):489-508.

4. Bolton WA. Clinical application of a tooth-size analysis. Am J Orthod. 1962;48(7):504-529.

5. Bolton WA. Disharmony in tooth size and its relation to the analysis and treatment of malocclusion. Angle Orthod. 1958;28(3):113-130.

6. Bhoyar AG. Esthetic Closure of Diastema by Porcelain Laminate Veneers: A Case Report. People's Journal of Scientific Research 2011;4(1):47-50.

7. Dietschi D. Free-hand composite resin restorations: A key to anterior aesthetics. Pract Periodont Aesthet Dent. 1995;7(7):15-25. 